\title{
ÓLEOS LUBRIFICANTES AUTOMOTIVOS RESIDUAIS: UM ESTUDO DE CASO EM LOGÍSTICA REVERSA
}

\section{WASTE AUTOMOTIVE LUBRIFICANTS OILS: A CASE STUDY IN REVERSE LOGISTICS}

Lucas Mello Schuelter ${ }^{1}$; Christiane Wenck Nogueira Fernandes ${ }^{2}$; Silvia Lopes de Sena Taglialenha ${ }^{3}$

\author{
Universidade Federal de Santa Catariana - Departamento de Engenharias da \\ Mobilidade, Joinville, SC \\ lucass@grad.ufsc.br ${ }^{1}$; chistiane.fernandes@ufsc.br ${ }^{2}$; s.taglialenha@ufsc.br ${ }^{3}$
}

RESUMO - A logística reversa de óleos lubrificantes residuais é abordada neste trabalho tendo como base as considerações apresentadas na Política Nacional de Resíduos Sólidos-Lei №. 12.305/2010, regulamentada pelo Decreto № 7.404/2010. Através de um estudo de caso são apontadas as especificidades dos processos de coleta, armazenagem, manuseio, transporte e destinação destes produtos em uma empresa coletora e são identificadas as fontes de riscos aos quais estão expostos os trabalhadores e meio ambiente e, por fim, sugerem-se melhorias no processo da empresa para eliminar ou amenizar estes riscos. A metodologia utilizada considerou dados obtidos através de entrevistas aplicadas durante visitas à empresa coletora. Dentre as melhorias propostas, indica um programa mais efetivo do uso de equipamentos de proteção individual e elaboração de um plano de ação emergencial.

Palavras-chave: logística reversa; óleos lubrificantes residuais; Política Nacional de Resíduos Sólidos.

ABSTRACT - The reverse logistics of waste automotive lubrificants oils is discussed in this work based on the considerations presented in the National Solid Waste Law 12.305/2010, regulated by Decree-low $7.404 / 2010$. Through a case study is point out the specifics of collection processes, storage, handling, transportation and disposal of these products in a disposal company and the risk sources that the workers and the environment are exposed. Finally, it is suggested that improvements in business process to eliminate or mitigate these risks. The methodology considered data obtained through interviews

Recebido em: 04/03/2016 Revisado em: 27/06/2016 Aprovado em: 05/08/2016 applied during visits to the sewage company. Among the proposed improvements, indicates a more effective program of use of personal protective equipment and preparation of an emergency action plan.

Keywords: reverse logistic; waste lubricants oils; National Solid Waste. 


\section{INTRODUÇÃO}

Os óleos lubrificantes residuais possuem produtos resultantes da sua utilização, principalmente metais pesados, que podem ser extremamente prejudiciais à saúde humana e ao meio ambiente, podendo provocar desde lesões na pele até câncer (SINDIREPA/SP, 2008). A preocupação com as questões ambientais tem se tornado cada vez maior e apesar disso, muita pessoas não conhecem o risco ambiental e à saúde destes produtos oriundos da utilização de óleos lubrificantes. Os óleos lubrificantes não são solúveis em água, não são biodegradáveis, impedem a passagem de oxigênio através de outros meios por formarem películas impermeáveis e ainda espalham substâncias tóxicas.

Geralmente a troca do óleo lubrificante dos automóveis é feita em concessionárias, oficinas ou postos de gasolina. Para que um estabelecimento possa realizar a troca, é necessário estar adequado às leis que regulamentam o manuseio $e$ armazenagem destes produtos.

Uma das possíveis destinações dos óleos lubrificantes residuais diz respeito à reciclagem do produto, sendo até 0 momento a única saída ambientalmente correta para o destino do mesmo, evitando a emissão de gases poluentes e metais pesados no ar, no caso da combustão dos lubrificantes.

Analisar o fluxo de óleos lubrificantes residuais é importante para que se avalie sua destinação final e se possa evitar desperdícios, como custos de transporte, de armazenagem, bem como eliminar ou diminuir os riscos causados por estes produtos. Além disso, o mapeamento destes fluxos pode auxiliar na localização de possíveis falhas no processo de recolhimento, transporte e armazenagem dos produtos.

Neste trabalho apresenta-se um mapeamento dos processos logísticos referentes à coleta, armazenagem, manuseio, transporte e destinação final dos óleos lubrificantes residuais em uma empresa autorizada a realizar estes serviços.

\section{LOGISTICA E LOGÍSTICA REVERSA}

A logística, segundo Ballou (2006), é o processo que se refere às atividades de movimentação e armazenagem, facilitando o fluxo de produtos desde o ponto de aquisição da matéria-prima até ao ponto de consumo final, bem como os fluxos de informações que colocam os produtos em movimento, tendo como objetivo manter níveis de serviço adequados aos clientes a um custo razoável. A logística deriva do conceito de gestão coordenada de atividades inter-relacionadas e agrega valor a produtos e serviços 
essenciais para a satisfação das necessidades dos clientes.

O termo Logística vem sendo usado há muito tempo, e seu conceito existe desde os tempos das guerras. Líderes militares sempre utilizavam da logística para garantir suprimentos às frentes de batalha. Geralmente, as guerras exigiam grandes deslocamentos de muitas pessoas e materiais, gerando a necessidade de uma grande organização logística. Durante muito tempo, a logística foi encarada apenas como uma atividade militar.

Conforme Bussinger (2013), depois da Segunda Guerra Mundial foi que a logística passou a atingir também as atividades civis.

Durante a evolução dos conceitos da logística, principalmente nas últimas três décadas do século passado, as organizações começaram a perceber que uma boa gestão dos processos logísticos pode trazer inúmeros benefícios e então passaram a aplicar estes conceitos em seus processos.

Quando falamos em logística, sabemos que sua principal aplicação está nas organizações, em especial nas empresas, que precisam da eficiência logística para reduzir seus custos e aumentar a confiabilidade na entrega de seus produtos. Colocar os produtos certos, na hora certa, no local certo e com o menor custo possível é a meta principal da logística (BALLOU, 2001).
Moura (2006) esclarece que o desempenho da cadeia logística concentra-se nos clientes internos e externos, através da disponibilização de produtos e serviços que agreguem valor de tempo e lugar, e obedecendo às expectativas quanto ao custo, qualidade, rapidez, flexibilidade e inovação. Para isto, são realizadas múltiplas atividades, executadas pela própria empresa ou por outras organizações, como o transporte e armazenagem, com intervenção de múltiplos recursos (humanos, financeiros, tecnológicos), seguindo modelos de organização adequados. Este processo é ilustrado na Figura 1.

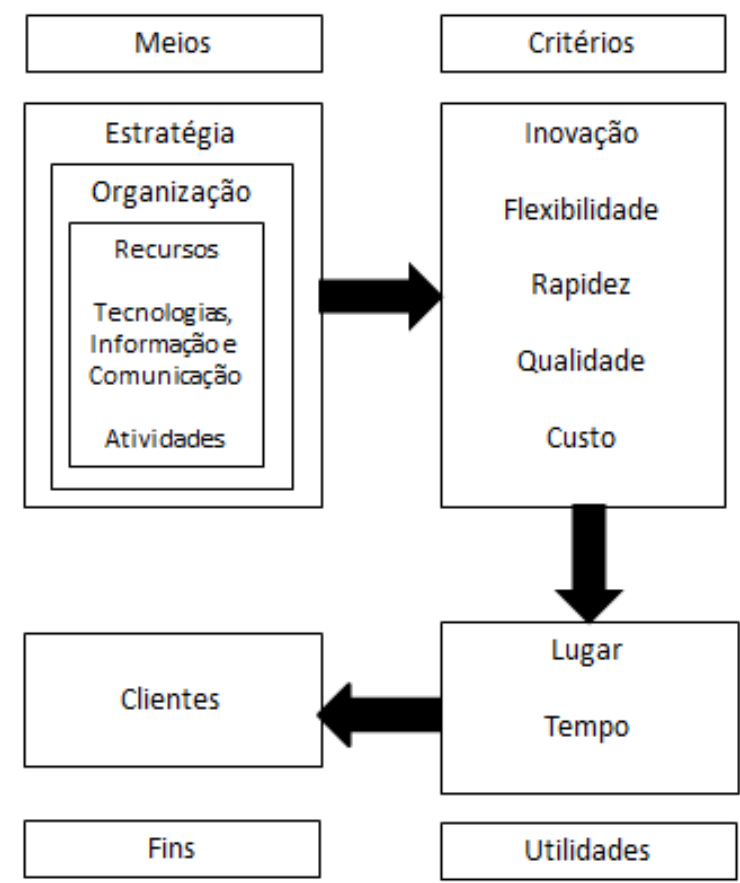

Figura 1. Visão do Processo Logístico. Fonte: Adaptado de Moura (2006).

Portanto, o sistema logístico apresenta alta complexidade. $\mathrm{O}$ gerenciamento de suas 
variáveis, que muitas vezes são conflitantes do ponto de vista da otimização dos processos logísticos, requer conhecimentos profundos, não só da logística como um todo, mas também dos seus subsistemas, das funções empresariais, bem como dos fatores que influenciam o relacionamento da organização com o ambiente externo.

A logística possui diversos ramos de estudo, sendo um deles a logística reversa. Assim como foi supracitado, pensa-se em logística basicamente como o fluxo de materiais desde a origem até o consumo.

\subsection{LOGÍSTICA REVERSA}

Motivadas por questões ambientais, as organizações vêm se tornando obrigadas pelas legislações atuais a gerenciar o fluxo reverso de seus produtos, ou seja, o retorno dos produtos depois que se encerra o seu ciclo de vida. A este fluxo dá-se o nome de logística reversa (LR).

Neste sentido, Lacerda (2009) define a LR como sendo o processo de planejamento, implementação e controle do fluxo de matérias-primas, estoque em processo e produtos acabados do ponto de consumo até o ponto de origem, com o objetivo de recapturar valor ou realizar um descarte adequado. Este processo gera materiais reaproveitados, que retornam ao processo logístico direto, gerando um novo produto. $\mathrm{O}$ autor ressalta que o processo logístico reverso é composto por coleta, separação, embalagem e expedição dos produtos usados, danificados ou obsoletos, desde o local de consumo até o local de reprocessamento, revenda ou descarte. E, dependendo das condições do material recolhido, ele pode sofrer diferentes tipos de reprocessamento, dentre eles: retorno ao fornecedor, revenda, recondicionamento, reciclagem ou, em último caso, descarte.

Figura 2. Distribuição direta e reversa.

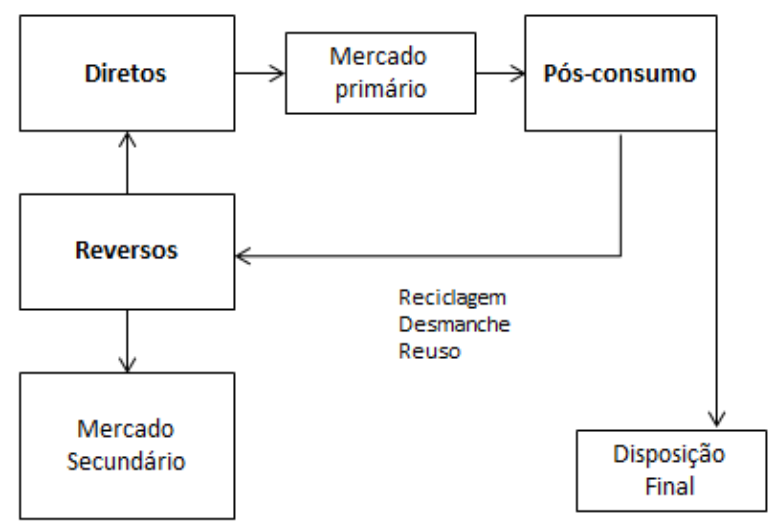

Fonte: Adaptado de Leite (2009).

Segundo Stock apud Leite (2009), em uma perspectiva de negócios, o termo logística reversa refere-se ao papel da logística no retorno de produtos, redução na fonte, reciclagem, substituição de materiais, reuso de materiais, disposição de resíduos, reforma, reparação e remanufatura.

Segundo Leite (2009), em uma perspectiva de negócios, o termo logística reversa refere-se ao papel da logística no retorno de produtos, redução na fonte, reciclagem, substituição de materiais, reuso de materiais, disposição de resíduos, 
reforma, reparação e remanufatura. O autor salienta ainda que a logística reversa é a área da logística empresarial que planeja, opera e controla o fluxo e as informações logísticas correspondentes ao retorno dos bens de pósvendas e de pós-consumo ao ciclo de negócio ou ao ciclo produtivo, por meio dos canais de distribuições reversos, agregando valores de natureza econômica, ecológica, legal, logística, de imagem coorporativa, entre outros.

Daher, Silva e Fonseca (2006) apresenta os benefícios do bom gerenciamento da logística reversa e os motivos pelos quais as organizações estão aumentando seus esforços quanto ao processo reverso: a legislação ambiental, que obriga empresas de determinados setores a retornarem seus produtos e realizar $\mathrm{o}$ reprocessamento dos mesmos; os benefícios econômicos, através da redução de custos trazida pelo reaproveitamento de materiais, o que diminui os gastos tanto com compra de matéria prima quanto com o descarte; como também, a crescente conscientização ambiental dos consumidores, que vêm exigindo uma postura correta das organizações quanto ao meio ambiente.

De tal modo, a logística reversa vem sendo citada cada vez com maior frequência em livros, artigos e outras publicações sobre Logística Empresarial. Pokharel e Mutha (2009), afirmam que a LR tem recebido atenção considerável devido aos potenciais de valorização dos produtos utilizados; além de, legislações e diretrizes, da consciência do consumidor e da responsabilidade social com o meio ambiente (CRUZ-RIVERAA E ELTELB, 2009; SRIVASTAVA, 2008; LEITE, 2009).

Assim como os pesquisadores da área, o mercado atual vem dando cada vez mais importância para a logística reversa, principalmente por ter se transformado em uma área estratégica. Conforme Lora (2000), as empresas estão tomando um comportamento ambiental ativo, transformando uma postura passiva em oportunidades de negócios.

No entanto, segundo Daher, Silva e Fonseca (2006), apesar de muitas empresas saberem a importância do fluxo reverso, grande parte delas tem dificuldade ou desinteresse em implementar o gerenciamento da LR.

A seguir será apresentada a LR de Óleos Lubrificantes.

\section{3. ÓLEOS LUBRIFICANTES}

Os óleos lubrificantes estão entre os produtos que possuem melhor estruturação de cadeia reversa. Monteiro (2010) afirma que os óleos lubrificantes são produtos elaborados com a finalidade principal de diminuir o atrito e o desgaste entre as partes móveis de um objeto. Dependendo da aplicação, estes produtos podem ainda 
exercer função de refrigeração, limpeza, transmissão de força mecânica, vedação, entre outras funções. No caso dos automóveis, o óleo lubrificante exerce a função de evitar o contato direto dos pistões com os cilindros do motor, além de vedar, refrigerar e limpar o motor.

Segundo (LUBES EM FOCO, 2014), a produção brasileira de lubrificantes não atende à demanda do mercado interno. Do total consumido no ano de 2012, 43\% foi proveniente de produção nacional, enquanto $39,5 \%$ tiveram como origem a importação e apenas $17,5 \%$ do volume consumido foi abastecido pela indústria de re-refino.

\section{1. ÓLEOS LUBRIFICANTES RESIDUAIS (OLR)}

Durante a utilização de óleos lubrificantes, diversos fatores podem influenciar a alteração de viscosidade do mesmo, diminuindo sua eficiência. Quando degradado, o óleo lubrificante pode causar desgaste indevido das partes mecânicas, cujos prejuízos podem ser irreversíveis (NETO, 2005). Dessa maneira, é necessário substituir o óleo lubrificante, para garantir a integridade e bom funcionamento do motor. A partir do momento em que isso acontece, 0 mesmo passa a ser um resíduo perigoso, por ser bastante contaminante.

Com base no SINDIREPA/SP (2008), mesmo o óleo lubrificante residual ainda possui de 80 a $85 \%$ de óleo lubrificante básico. Posteriormente, através de diversos processos tecnológicos, é possível extrair este lubrificante básico do resíduo, com as mesmas propriedades e características do refino inicial. Por isso, o processo chamado de re-refino, foi adotado pelo Conselho Nacional do Meio Ambiente CONAMA, através da Resolução №362/2005, como o destino obrigatório dos óleos lubrificantes residuais.

\subsection{COLETA E DESTINAÇÃO DE OLR}

O processo de coleta e destinação correta apresenta cinco participantes envolvidos, que possuem determinadas obrigações durante o processo, conforme Tabela 1.

Assim, depois de retirado o óleo lubrificante residual, deve ser entregue a um coletor credenciado pela ANP (Agência Nacional de Petróleo, Gás Natural e biocombustíveis). Ainda, o SINDIREPA/SP (2008) estabelece que o coletor deve realizar determinados testes a fim de verificar a existência de alguma espécie de contaminação que inviabilize ou retire a eficiência do processo de re-refino. Após os testes e verificadas a possibilidade do rerefino do óleo, o mesmo é encaminhado a um re-refinador, que pode ou não ser a mesma empresa que realiza a coleta.

De acordo com informações da Indústria Petroquímica do Sul - IPS (2014), o 
processo de re-refino consiste nas seguintes atividades: Recebimento e filtração; Termo craqueamento e desidratação: Evaporação total; Tratamento físico-químico; Clarificação; Filtração. Ao final destes processos, obtém-se novamente o óleo lubrificante básico, o qual atende as mais altas exigências de um óleo lubrificante básico mineral e que posteriormente receberá aditivos e será comercializado novamente.
A Resolução no 450/2012 do CONAMA, em seu artigo 9o, estabelece que:

"o Ministério do Meio Ambiente, na segunda reunião ordinária do Conselho Nacional do Meio Ambiente-CONAMA, de cada ano, apresentará o percentual mínimo de coleta de óleo lubrificante usado ou contaminado [...]".

Tabela 1. Participantes envolvidos no processo de coleta dos óleos lubrificantes.

\begin{tabular}{l|l|l}
\hline \multicolumn{1}{c|}{ Atores } & \multicolumn{1}{|c}{ Identificação } & \multicolumn{1}{c}{ Obrigações } \\
\hline $\begin{array}{l}\text { Produtores e } \\
\text { importadores }\end{array}$ & $\begin{array}{l}\text { Empresas que fornecem o óleo } \\
\text { lubrificante acabado ao mercado }\end{array}$ & $\begin{array}{l}\text { Custear a coleta e informar aos } \\
\text { consumidores (geradores) as } \\
\text { obrigações destes, bem como os } \\
\text { riscos ambientais do descarte } \\
\text { incorreto }\end{array}$ \\
\hline $\begin{array}{l}\text { Revendedore } \\
\text { s }\end{array}$ & $\begin{array}{l}\text { Empresas que comercializam o } \\
\text { óleo lubrificante acabado }\end{array}$ & Recolher dos geradores o óleo usado \\
\hline Geradores & $\begin{array}{l}\text { Pessoas físicas ou jurídicas que } \\
\text { utilizam o óleo lubrificante }\end{array}$ & $\begin{array}{l}\text { Entregar o óleo usado ao ponto de } \\
\text { recolhimento }\end{array}$ \\
\hline Coletores & $\begin{array}{l}\text { Empresas licenciadas pelo órgão } \\
\text { ambiental competente e pela } \\
\text { ANP }\end{array}$ & $\begin{array}{l}\text { Realizar a coleta e entregar ao re- } \\
\text { refinador }\end{array}$ \\
\hline $\begin{array}{l}\text { Re- } \\
\text { refinadores }\end{array}$ & $\begin{array}{l}\text { Empresas autorizadas pela ANP e } \\
\text { licenciada por órgão ambiental } \\
\text { competente }\end{array}$ & $\begin{array}{l}\text { Remover os contaminantes do óleo } \\
\text { usado, transformando-o em óleo } \\
\text { lubrificante básico }\end{array}$ \\
\hline
\end{tabular}

Fonte: (Adaptado de SOHN, 2007)

Os percentuais estabelecidos neste artigo são mostrados na Tabela 2.

Tabela 2. Percentuais mínimos de coleta de OLU por região do país

\begin{tabular}{l|c|c|c|c}
\hline \multirow{2}{*}{ Regiões } & \multicolumn{4}{|c}{ Ano } \\
\cline { 2 - 5 } & 2012 & 2013 & 2014 & 2015 \\
\hline Nordeste & 26 & 38 & 40 & 52 \\
\hline Norte & 26 & 28 & 30 & 31 \\
\hline $\begin{array}{l}\text { Centro - } \\
\text { oeste }\end{array}$ & 32 & 33 & 34 & 35 \\
\hline
\end{tabular}

\begin{tabular}{l|c|c|c|c}
\hline Suldeste & 42 & 42 & 42 & 42 \\
\hline Sul & 36 & 36 & 37 & 37 \\
\hline Brasil & 36,9 & 37,4 & 38,1 & 38,5 \\
\hline
\end{tabular}

Fonte: (BRASIL. MME / MMA, 2012).

\subsection{EFEITOS DA DESTINAÇÃO INCORRETA DE OLU}

Segundo entidades reconhecidas internacionalmente, devido à dificuldade em fiscalização da destinação do OLU, o resíduo 
é utilizado em inúmeras aplicações ilegais tais como queima em substituição ao óleo combustível, em correntes de motosserra e despejados diretamente na rede pública de esgotos ou na rede de drenagem pluvial, em corpos hídricos ou no solo. Embora proibida no Brasil, a queima é uma forma comum de desvio dos óleos lubrificantes usados, coletados por empresas não licenciadas.

O SINDIREPA/SP (2008) informa que o óleo residual apresenta contaminantes que são altamente prejudiciais à saúde humana, como o chumbo, o cádmio, o arsênio, o cromo, dioxinas e hidrocarbonetos policíclicos aromáticos. Estes contaminantes podem acarretar intoxicação aguda, intoxicação crônica, câncer de pele, pulmão, fígado e traqueia, doenças pulmonares, entre diversas outras doenças.

Pio (2010) ensina que, além de espalharem substâncias tóxicas, não se dissolvem na água, formando películas impermeáveis que impedem a passagem de oxigênio tanto na água quanto no solo. A queima indevida causa sérios problemas de contaminação do ar, liberando substâncias como cloro, fósforo e enxofre.

Por estes motivos, os óleos lubrificantes residuais devem ser corretamente manuseados, armazenados e ter uma destinação final controlada.

\section{METODOLOGIA}

Segundo Silva e Menez (2005), existem diversas formas de classificação de pesquisas, conforme seu ponto de vista. Do ponto de vista da forma de abordagem, este estudo pode ser classificado como uma pesquisa qualitativa, por tratar da interpretação dedos fenômenos e a atribuição de significados e por haver a ausência da estatística na análise dos dados.

Segundo Neves (1996), a pesquisa qualitativa compreende um conjunto de técnicas interpretativas que visam descrever e decodificar os componentes de um sistema.

Ainda segundo a classificação proposta por Silva e Menez (2005), do ponto de vista dos procedimentos técnicos adotados, o presente estudo pode ser classificado em seu primeiro momento como uma pesquisa bibliográfica, com o objetivo de expor os conceitos dos assuntos que serão tratados ao longo do mesmo. Em um segundo momento, realiza-se um estudo de caso, onde é feito o levantamento de informações em uma empresa que realiza o serviço de logística reversa de óleos lubrificantes residuais, buscando descrever cada etapa do processo.

\subsection{A EMPRESA}

Para realizar o estudo de caso, escolheu-se uma empresa no estado de Santa Catarina, que é a primeira e única 
empresa a realizar a coleta de óleos lubrificantes residuais no estado, atuando desde 1994. Localizada na cidade de Araquari, a empresa atende os estados do Paraná e Santa Catarina. Inicialmente, apenas comercializava e realizava o serviço de troca de óleos. Com o passar do tempo, ocorreu o interesse de outras empresas em comprar o óleo usado que ela retirava dos automóveis. Depois disso, em 1999, passaram a desenvolver uma cadeia de coleta de óleos lubrificantes residuais em outros postos de serviços, e revender os mesmos. Seus principais clientes e pontos de coleta se referem ao setor automotivo. Também oferece outros serviços variados, ligados ao gerenciamento de resíduos.

\subsection{COLETA DE DADOS}

A coleta dos dados para o estudo foi feita por meio de uma entrevista não estruturada. Este método permitiu o direcionamento das perguntas conforme a evolução dos assuntos abordados. Assim, foram obtidas outras informações durante a entrevista que não tinham sido contempladas no roteiro. Outras dúvidas foram esclarecidas via correio eletrônico.

Os dados foram organizados de maneira a descrever os processos envolvidos nas atividades de armazenagem, manuseio, coleta, transporte e destinação dos óleos lubrificantes residuais, e possibilitar a sugestão de melhorias nestes processos, com o intuito de melhorar a eficiência do mesmo e eliminar ou diminuir os riscos apresentados no processo.

\section{RESULTADOS E DISCUSSÕES}

O processo realizado pode ser comparado a um processo de revenda, porém reverso. Em um processo de revenda comum, os produtos são comprados de um distribuidor e vendidos aos consumidores finais. No caso estudado, os resíduos são recolhidos de vários postos de serviços e consolidados em uma carga maior que é revendida a um re-refinador. Este, por sua vez, realiza o processo de re-refino e revende o óleo básico como matéria prima para um produtor de óleos lubrificantes.

É importante salientar que, em toda a movimentação, entende-se que todos os players envolvidos são corresponsáveis pela coleta, manuseio, armazenagem, transporte e destinação. Portanto, por exemplo, mesmo que não esteja mais em posse do óleo que foi retirado dos automóveis de seus clientes, uma oficina pode vir a ser corresponsável por algum acidente que possa acontecer durante o transporte entre a coletora e a rerefinadora.

O processo de logística reversa dos óleos residuais na empresa estudada referese às etapas destacadas na Figura 3 , que mostra toda a cadeia logística envolvida. 
O processo reverso inicia quando os consumidores finais procuram os postos de serviços para realizarem a troca de óleo. Os postos realizam as trocas, guardando o óleo residual retirado dos veículos. A partir daí, a empresa coletora procura os postos de serviços e realiza a coleta deste resíduo e dá continuidade ao processo, entregando à rerefinadora, que trata o resíduo e o devolve para o início da cadeia.

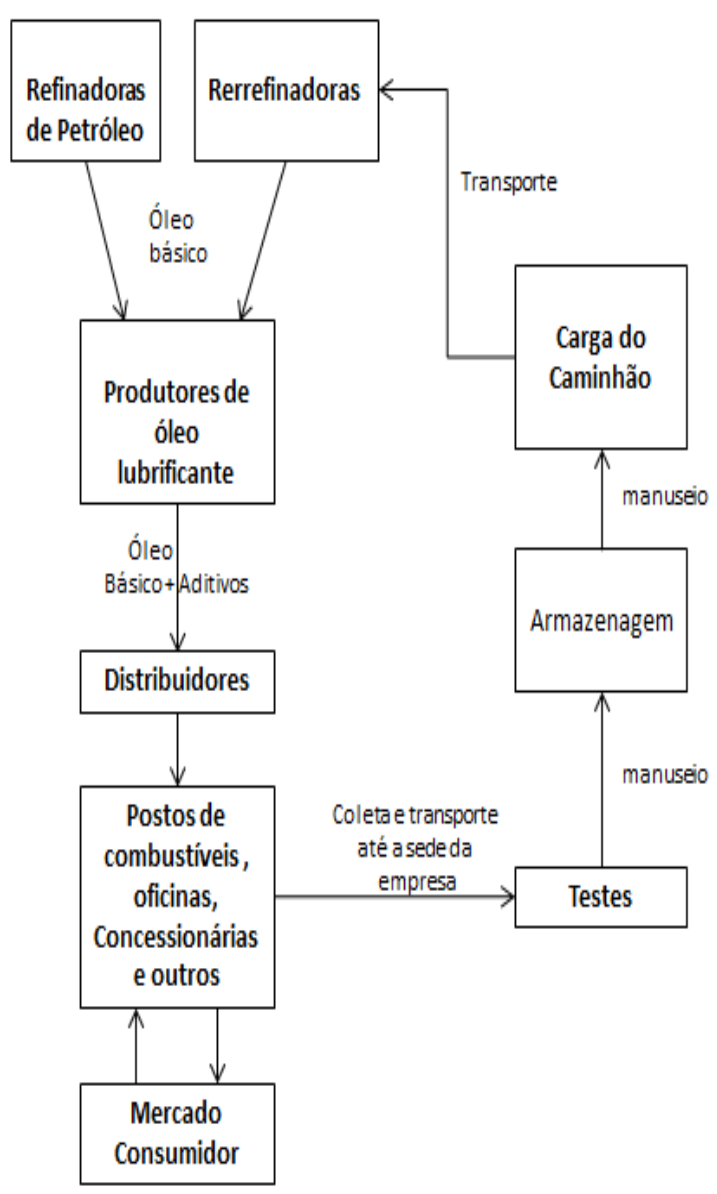

Figura 3: Processos realizados pela empresa Fonte: elaborado pelo autor.

Além do óleo, são recolhidos alguns resíduos sólidos, como estopas, filtros usados, serragem e o que mais estiver contaminado com óleo. Estes, que não fazem parte da cadeia acima, são destinados a aterros sanitários, pois não há como efetuar qualquer tipo de reuso ou reciclagem.

\subsection{COLETA DO OLR}

A coleta é feita através de caminhões que saem da base em Joinville pelo próprio motorista.

Os motoristas fazem o trabalho de visitar todos os postos de serviços possíveis na região para verificar a necessidade de coleta do que estiver disponível. A área de coleta da empresa estudada abrange os estados de Santa Catarina e Paraná. No estado catarinense, a atuação se dá desde toda a extensão do litoral até o meio oeste, e no estado vizinho as coletas ocorrem na região sudoeste, com destaque para a região compreendida na área do triângulo entre Ponta Grossa/PR, Paranaguá/PR e Itajaí/SC.

Os caminhões possuem capacidade de armazenagem definida e contam com um sistema de mangueiras e bombas para sucção dos resíduos diretamente do reservatório de cada posto de serviço. No momento da coleta, a empresa emite um Certificado de Coleta, que serve como documento fiscal que comprova a data, quantidade de resíduo coletada de cada posto de serviço e valor pago pelo mesmo.

A coleta tem demanda variável e observa-se uma tendência de aumento de troca de óleos com a aproximação do final de 
ano. Passada a virada de cada ano, a demanda cai consideravelmente durante os três primeiros meses do ano seguinte. Nos meses seguintes, a tendência de demanda é respeitar a média anual, sem picos.

Em indústrias como a portuária, a programação de coleta é semanal e é possível completar um caminhão todo em apenas uma única coleta.

\subsection{MANUSEIO E TESTES}

O manuseio dos óleos lubrificantes automotivos residuais é feito basicamente através dos equipamentos instalados nos próprios caminhões. Cada caminhão conta com uma bomba e uma mangueira de uma polegada de diâmetro com válvula para sucção e uma mangueira de duas polegadas de diâmetro com válvula para a descarga. No final de cada mangueira de sucção, existe um filtro que tem como objetivo evitar a sucção de quaisquer resíduos sólidos que possam estar dentro dos tanques.

Ao chegar à empresa, a descarga é realizada através de gravidade. Como os tanques são construídos abaixo do nível do solo, o caminhão estaciona sobre o mesmo e realiza a descarga. Para carregar os caminhões de maior porte e enviar à destinação final, o procedimento é basicamente o mesmo que na coleta: uma mangueira é colocada no interior do tanque e, através de uma bomba de sucção, o caminhão é abastecido.

Antes da realização da descarga do resíduo coletado, é feito um teste com soda cáustica, misturando o produto a uma amostra do óleo coletado e aquecendo a mistura. Caso ele se transforme em graxa ao fim do processo, o óleo é considerado impróprio para re-refino, sendo armazenado em outro tanque. Durante o manuseio do óleo, é exigido dos funcionários sempre o uso de equipamentos de segurança, como sapatão fechado e luvas. Os caminhões são equipados, ainda, com outros equipamentos como baldes e pás a fim de auxiliar em eventuais emergências.

\subsection{ARMAGENAGEM E TRANSPORTE}

A armazenagem do óleo na sede da empresa é feita em quatro tanques, sendo três destinados a óleos próprios para rerefino e um para óleos impróprios. Quando for possível realizar o fechamento de uma carga, a empresa verifica dentre seus clientes quais estão comprando os resíduos no momento e negocia a venda. O tempo médio que as cargas ficam armazenadas até serem consolidadas em uma maior é de dois a três dias.

É importante salientar que o pátio e o sistema de tancagem também devem ser licenciados pelos órgãos competentes, passando por auditorias periódicas para 
aferição de suas características. O mesmo acontece com os veículos.

\subsection{DESTINAÇÃO}

Cada carga é destinada às rerefinadoras juntamente com os Certificados de Coleta emitidos no momento da compra dos resíduos em cada posto de serviço. Assim, elas podem prestar contas aos órgãos ambientais e produtores de óleo. Estes certificados servem como prova de que foi coletada e re-refinada a quantidade mínima estabelecida nas leis.

Além do re-refino, todo o óleo impróprio para este processo pode ser ainda usado para fabricação de graxas, um processo feito geralmente pela própria rerrefinadora. Porém, o valor comercial e a demanda do óleo impróprio são muito baixos, e algumas vezes o valor obtido na revenda não cobre os custos de transporte para que se leve este resíduo até as rerrefinadoras. Por isso, em alguns casos, este resíduo é destinado a aterros, juntamente com os resíduos sólidos coletados.

\subsection{RISCOS IDENTIFICADOS}

Todo o processo apresenta grande número de fontes de riscos para o meio ambiente ou para a saúde das pessoas envolvidas. Para os trabalhadores, o maior risco ocorre pela possibilidade de contato dos óleos com a pele ou olhos. Os hidrocarbonetos presentes nos óleos lubrificantes, em contato com a pele, entram profundamente nos poros, podendo causar doenças como câncer cutâneo ou contaminação por germes responsáveis por infecções.

As pessoas próximas aos locais onde ficam armazenados óleos lubrificantes residuais podem ser expostas ao ar contaminado com agentes tóxicos, proveniente de reações químicas que geralmente acontecem dentro dos tanques de armazenamento. O trabalhador está exposto ainda a um alto nível de ruído, devido à proximidade com o motor do caminhão, bombas e equipamentos, no momento de carga e descarga dos resíduos coletados, e riscos gerais pelo trabalho em ambiente externo, como condições meteorológicas.

$\mathrm{Na}$ questão ambiental, o maior risco encontra-se na possibilidade de vazamentos, tanto nos tanques de armazenagem como nos caminhões, fazendo com que o óleo residual entre em contato direto com o meio ambiente, podendo poluir rios, canais e mananciais, bem como impedir a oxigenação do solo e impossibilitar a continuidade de diversos tipos de vida.

A poluição por vazamento de óleos lubrificantes pode ser de difícil reversão. Por não ser biodegradável, o resíduo leva dezenas de ano para desaparecer do meio ambiente, multiplicando as consequências 
causadas pelo mesmo. Para prevenir estes riscos, a empresa realiza a entrega de equipamentos de proteção individual para os trabalhadores e os orienta para os casos de emergência mais graves. Apesar disso, não existe uma política de cobrança do uso destes equipamentos por parte dos trabalhadores e o treinamento para casos emergenciais é apenas teórico e passado apenas uma vez para cada trabalhador.

\section{SUGESTÃO PARA MINIMIZAÇÃO DOS RISCOS ENVOLVIDOS NO PROCESSO}

Depois de realizada a identificação dos riscos envolvidos nas atividades de coleta, manuseio, armazenagem e transporte dos óleos lubrificantes automotivos residuais, foram elaboradas sugestões para que estes sejam minimizados. Para amenizar os riscos aos trabalhadores envolvidos nos processos, foram propostas as seguintes ações:

- Adoção de equipamentos de menor intervenção humana, como sistemas de sucção mais modernos, no qual os trabalhadores não correm o risco de contato com o resíduo;

- Uso de Equipamentos de Proteção Individual (EPIs), dentre os quais luvas de policloreto de vinila ou neoprene, cremes protetores, mangas de proteção, macacão, proteção respiratória, óculos de proteção, capacete, calçado resistente e impermeável e protetor auricular;
- Exigência ostensiva por parte da empresa para que os trabalhadores usem estes EPIs;

- Implementação de um programa de revisão, limpeza e troca dos EPIs;

- Manutenção de fichas com identificação de medidas de primeiros socorros e formas de intoxicação das substâncias presentes no processo.

Para diminuir o risco de contaminação ao meio ambiente, a empresa tem a possibilidade de elaborar um processo de verificação contínua externa visual dos tanques, realizar, periodicamente, o esvaziamento total dos tanques para verificação das condições dos mesmos, ou ainda adoção de sistemas mais modernos de busca por fissuras ou trincas, como ultrassom e adotar um planejamento de manutenção preventiva rigoroso para os caminhões.

Além destas, como prevenção geral, a empresa pode, ainda elaborar um plano de ação emergencial, para situações adversas que podem vir a ocorrer durante todo o processo; realizar, periodicamente, treinamento dos funcionários quanto às fichas de medidas de primeiros socorros e ao plano de ação emergencial, com simulações de situações de emergência; implementar um plano de conscientização dos riscos envolvidos na atividade, com o objetivo de sensibilizar os trabalhadores a tomarem todas as medidas necessárias para a 
segurança deles mesmos e do meio ambiente. Através das medidas citadas, a empresa pode usufruir de maior segurança e de controle total dos riscos apresentados durante sua operação.

\section{CONSIDERAÇÕES FINAIS}

No decorrer das pesquisas realizadas, percebeu-se a evolução dos conceitos de Logística Reversa e a importância da aplicação dos mesmos no dia a dia das empresas. A destinação correta dos óleos lubrificantes automotivos residuais deve ser um processo realizado com o máximo de planejamento e cuidados, pois qualquer desvio do que é considerado ideal na cadeia logística reversa destes resíduos pode trazer sérias consequências.

O efetivo estabelecimento da logística reversa depende de dois fatores: incremento das atividades de pesquisa e inovação tecnológica e a criação de um mercado para produtos reciclados.

No que se refere aos custos do sistema, a implementação de um processo de Logística Reversa, além de conduzir à satisfação de exigências normativas, como a Política Nacional de Resíduos Sólidos-Lei №. 12.305 , pode levar a uma redução de custo no produto acabado, principalmente quando existe o reuso do material de descarte.

$\mathrm{Na}$ empresa estudada foi possível avaliar os processos de armazenagem, manuseio, coleta, transporte e destinação dos óleos lubrificantes automotivos residuais, bem como identificar as fontes de riscos presentes.

Ainda, foram levantadas possibilidades de melhorias, principalmente nos procedimentos de segurança, tentando amenizar ao máximo a exposição a estas fontes de riscos, descrevendo as particularidades dos processos realizados pela empresa.

Através do estudo, concluiu-se que a empresa deve elaborar programas e políticas objetivando diminuir ao máximo o contato direto dos seus trabalhadores com os resíduos coletados, bem como evitar que estes entrem em contato com o meio ambiente. A empresa deve, ainda, estar preparada da melhor forma possível para conter quaisquer tipos de acidentes ou desvios em seu processo, com o objetivo de diminuir o impacto que os mesmos possam causar.

Mesmo apresentando os riscos citados, o processo realizado na empresa coletora é de extrema importância para a cadeia logística dos óleos lubrificantes automotivos, pois a falta de controle sobre os mesmos pode resultar em uma destinação muito mais nociva à saúde da população e à preservação do meio ambiente, como é o caso da queima ilegal destes resíduos, destinação está que já 
foi muito comum e que se pretende extinguir.

Para que o sistema logístico reverso tenha resultado eficaz, é necessário que haja conhecimento e comprometimento de todos os componentes da cadeia, desde o produtor até o consumidor final, ou seja, é necessário que se tenha responsabilidade compartilhada entre todos os envolvidos na cadeia de suprimento.

Já que a produção brasileira de lubrificantes não atende à demanda do mercado interno, é de fundamental importância devolver este produto como matéria prima à cadeia produtiva, contribuindo, sobretudo, para o desenvolvimento sustentável, econômico e corporativo da sociedade.

\section{REFERÊNCIAS}

ANP - AGÊNCIA NACIONAL DO PETRÓLEO, GÁS NATURAL E BIOCOMBUSTÍVEIS.

Disponível em:

http://www.anp.gov.br/wwwanp- Acesso em: 15 de maio de 2014.

BALLOU, R. H. Gerenciamento da cadeia de abastecimento: planejamento, organização e logística empresarial. 4. ed. Porto Alegre: Bookman, 2001.

BALLOU, R. H. Gerenciamento da cadeia de suprimentos: logística empresarial. 5. ed. Porto Alegre: Bookman, 2006.

BRASIL. Ministério de Minas e EnergiaMinistério do Meio Ambiente. Portaria interministerial no 59, de 17 de fevereiro. Lex: Diário Oficial da União no 37, Brasília, p. 48, 23 de fevereiro, 2012.

BUSSINGER, V. O que é logística? In: Instituto de Desenvolvimento, Logística, Transporte e Meio Ambiente. 2013. Disponível em: <http://www.e-commerce.org.br/artigos/ logistica.php>. Acesso em: 17 out. 2014. CONAMA - CONSELHO NACIONAL DO MEIO AMBIENTE. Altera os arts. 90, 16, 19, 20, 21 e 22, e acrescenta 0 art. 24 à Resolução no. 362, de 23 de junho de 2005, do CONAMA, que dispõe sobre recolhimento, coleta e destinação final de óleo lubrificante usado ou contaminado. Resolução no 450, de 06 de março de 2012. Lex: Diário Oficial da União no 46, Brasília, p. 61, 07 de março, 2012.

CRUZ-RIVERAA, R.; ELTELB, J. Reverse logistics network design for the collection of End-of-Life Vehicles in Mexico. European Journal of Operational Research, v. 196, n. 3, p. 930-939, 2009. https://doi.org/10.1016/i.ejor.2008.04.041 DAHER, C. E.; SILVA, E. P. S.; FONSECA, A. P. Logística Reversa: oportunidade para redução de custos através do gerenciamento da cadeia integrada de valor. Brazilian Business Review, v. 3, n. 1, p. 58-73, 2006. IPS - Indústria Petroquímica do Sul. Rerrefino. 2014. Disponível em: <http:// www.ips.ind.br/>. Acesso em: 22 out. 2014. LACERDA, L. Logística reversa: uma visão sobre os conceitos básicos e as práticas operacionais. In: Centro de Estudos em Logística - COPPEAD. 2009. Disponível em: $<$ www.cel.coppead.efrj.br>. Acesso em: 14 abril 2014.

LEITE, P. R. Da logística empresarial à logística reversa. Revista Banas Qualidade, n. 169, 2006.

LEITE, P. R. Logística reversa: meio ambiente e competitividade. 2. ed. São Paulo: Pearson Prentice Hall, 2009.

LORA, E. S. Prevenção e controle da poluição nos setores energéticos, industrial e de transporte/Electo Silva Lora. Brasília: ANEEL, 2000.

LUBES EM FOCO. Brasil produz apenas $43 \%$ de sua demanda de óleos básicos. 2014. Disponível em: <http://lubes.com.br/ 13031505.pdf>. Acesso em: 15 de maio de 2014.

MONTEIRO, T. S. Produção e aplicação de óleos lubrificantes industriais. Rio de Janeiro: UFRRJ, 2010. 
MOURA, B. Logística: conceitos e tendências. Lisboa: Centro Atlântico, 2006.

NETO, W. B. Parâmetros de qualidade de lubrificantes e óleo de oliva através de espectroscopia vibracional, calibração multivariada e seleção de variáveis. Campinas: UNICAMP, 2005.

NEVES, J. L. Pesquisa qualitativa: características, usos e possibilidades. Caderno de Pesquisas em Administração. São Paulo, vol. 1, no 3, 1996. Disponível em: <http://www.ead.fea.usp.br/cad-pesq/ arquivos/C03-art06.pdf>. Acesso em: 2 de julho de 2014.

PIO, L. S. Gerenciamento de óleos lubrificantes usados ou contaminados. Rio de Janeiro: Universidade Candido Mendes, 2010.

POKHAREL, S.; MUTHA A. Perspectives in reverse logistics: a review, resources. Conservation and recycling, 53 , n. 4 , p. $175-$ 182, 2009. https://doi.org/10.1016/j.resconrec.2008.11. $\underline{006}$

SILVA, E. L.; MENEZ, E. M. Metodologia da pesquisa e elaboração de dissertação. 4. ed. Florianópolis: UFSC, 2005.

SINDIREPA/SP - SINDICATO DA INDÚSTRIA DE REPARAÇÃO DE VEÍCULOS E ACESSÓRIOS DO ESTADO DE SÃO PAULO. Coletânea de literatura: universo da reparação automotiva. 2008. Disponível em <http://www.sindirepasp.org.

$\mathrm{br} / \mathrm{pdf} /$ COLETANEA_lubvol06.pdf $>$. Acesso em 25 de setembro de 2013.

SOHN, H. Guia básico: gerenciamento de óleos lubrificantes usados ou contaminados. São Paulo: Senai/SP, 2007.

SANTOS, D. F. et. al. A logística reversa como estratégia de sustentabilidade e redução de custos. Revista Meio Ambiente e Sustentabilidade, v. 4, n. 2, p. 226-242, 2013. SRIVASTAVA, S. K. Network design for reverse logistics. Omega, v.36, n.4, p.535-548, 2008. 